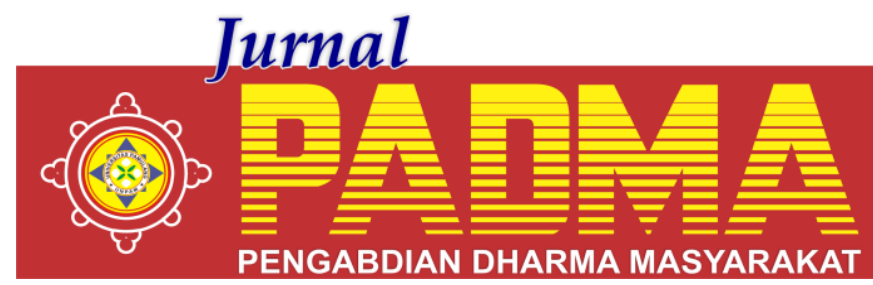

VOLUME 1, NOMOR I, JANUARI 2021

\title{
MENUMBUHKAN SEMANGAT PENGUSAHA MUDA SISWA
}

\author{
${ }^{1 *}$ Nariah, ${ }^{2}$ Suryadi Marthadinata, ${ }^{3}$ Reni Hindriari, ${ }^{4}$ Retno Japanis Permatasari, \\ 5Lia Asmalah \\ Universitas Pamulang, Tangerang Selatan, Banten, Indonesia \\ *dosen02459@unpam.ac.id
}

\begin{abstract}
Abstrak
Tujuan kegiatan ini adalah menumbuhkan semangat pengusaha muda ini sangat dibutuhkan sesuai dengan kebutuhan para siswa saat ini. Oleh sebab itulah pada PKM ini akan diberikan penyuluhan menumbuhkan semangat pengusaha muda siswa SMA 6 Tangerang Selatan. Dalam kegiatan ini metode yang diterapkan diharapkan dapat memberikan kemudahan kepada para mahasiswa SMA 6 Tangerang Selatan. Metode yang digunakan adalah metode diskusi kelompok, sharing, tanyajawab, praktik yang di damping oleh pemateri. Pada metode penjelasan, setiap instruktur menyampaikan materi terkait dan membuat tampilan visual berupa slide power point yang ditampilkan ke layar dengan LCD proyektor. Hasil kegiatan memberikan pemahaman baru kepada siswa dalam melakukan pengelolaan binis tidak harus selalu dengan nominal uang yang besar, atau mekanisme yang rumit. Mereka dapat melakukannya secara berkelompok, atau sendiri dari rumah. Siswa dapat mendapatkan ilmu pengetahuan baru, sehingga bisa dimaksimalkan potensi diri dengan kreatif dan inovatif.
\end{abstract}

Kata kunci: Wirausaha

The purpose of this activity is to foster the spirit of young entrepreneurs is needed in accordance with the needs of students today. That is why the PKM will be given counseling to foster the enthusiasm of young entrepreneurs of SMA 6 Tangerang Selatan students. In this activity the method applied is expected to provide convenience to students of South Tangerang 6 High Schools. The method used is the method of group discussion, sharing, question and answer, practice accompanied by the speaker. In the explanation method, each instructor conveys related material and makes a visual display in the form of a power point slide that is displayed on the screen with the projector's LCD. The results of activities provide new understanding to students in managing business not necessarily with large amounts of money, or complicated mechanisms. They can do it in groups, or alone from home. Students can get new knowledge, so they can maximize their potential with creativity and innovation.

Keywords: Entrepreneurship

\section{PENDAHULUAN}

SMA 6 Tangerang Selatan memiliki nama baik yang cukup bagus di mata masyarakat. Salah satu sekolah unggulan yang ada di Tangerang Selatan, SMA 6 Tangerang Selatan selalu berupaya mencetak lulusan yang tidak hanya cakap dalam bidang akademis dan non akademis, tetapi juga memiliki karakter yang siap bersaing dalam secara intelektual. Sebagai salah satu SMA Unggulan di Tangerang Selatan, SMA 6 Tangerang Selatan berkewajiban membentuk mindset dan ketrampilan peserta didiknya agar mampu bersaing di era milenial saat ini. Salah satunya adalah dengan mengembangkan skill kewirausahaan para siswa. Agar Siswa dapat memiliki semangat berwirausaha yang terstruktur sejak dini, mampu memetakan diri dan dapat membuat branding diri dan produk yang dibuat

Perlu upaya menumbuhkan kembali jiwa kewirausahaan siswa. Upaya itu tentu perlu dukungan dari semua pihak, tidak hanya sekolah, kewirausahaan merupakan suatu proses untuk mengembangkan atau menerapkan suatu ide inovatif dalam memanfaatkan peluang mendapatkan sesuatu yang bernilai. Sehingga, pengembangan potensi itu sangat baik diterapkan dalam diri sebagai bentuk manajerial dalam kehidupan.

Banyak orang yang keliru menganggap berwirausaha itu hanya berdagang saja. 
Padahal, berwirausaha itu bisa berupa apa saja. Perlu mengubah mindset pikiran agar siswa memiliki jiwa berwirausaha sejak dini. Karena sekarang ini, ketika lulus sekolah, anak-anak lebih menyukai sesuatu hal yang serba instan, yaitu lebih memilih bekerja menjadi buruh, dibandingkan membuka usaha atau berwirausaha.

Sekolah adalah untuk mencetak siswa agar memiliki suatu keahlian sebagai bekal menghadapi dunia kerja. Tapi akan lebih baik, jika siswa berinovasi untuk membuka usaha dan memiliki usaha sendiri. Dengan begitu dapat memberikan kesempatan kerja bagi orang lain. Dengan harapan di masa depan dengan berwirausaha pendapatan akan berbeda. Ketika menjadi pekerja, maka penghasilannya hanya mengsiswalkan gaji dari perusahaan yang diterima setiap bulan dengan nilai gaji yang sama. Sedangkan menjadi pengusaha pendapatannya tak terbatas, bergantung dari diri inovasi sendiri. Kalau ingin berpenghasilan banyak, usahanya lebih rajin dan waktupun kita yang menentukan. Hal itu sangat berbeda dengan pekerja.

Bagi sebagian orang, berjualan atau berwirausaha bukanlah suatu pekerjaan, melainkan sebuah profesi. Sedangkan menjadi buruh adalah suatu pekerjaan yang bisa disebut bekerja. Namun, tak jarang orang merasa malu jika dirinya berjualan atau usaha sendiri. Berbeda jika dirinya bekerja sebagai buruh, dengan pakaian rapi. Tetapi waktu diatur perusahaan dan pendapatan terbatas.

Program pengabdian kepada masyarakat merupakan salah satu program yang wajib dilaksanakan, baik oleh dosen maupun oleh mahasiswa, dengan berlsiswaskan pada prinsip-prinsip: motivasi pemenuhan kompetensi akademik, jiwa kewirausahaan (entrepreneurship), dan profesional, sehingga dapat menghasilkan program pengabdian kepada masyarakat yang bermutu, relevan, dan sinergis dalam meningkatkan pemberdayaan masyarakat.

Untuk itulah tim dosen program studi Manajemen mengadakan Pengabdian Kepada Masyarakat untuk menumbuhkan semangat pengusaha muda sebagai bentuk kepedulian kepada Siswa SMA 6 Tangerang Selatan. Pelatihan ini akan melakukan pendekatan kekinian sehingga dapat lebih mudah dipahami oleh siswa SMA 6 Tangerang Selatan yang rata-rata adalah pemuda dan remaja siswa yang up to date dengan keadaan saat ini.

Berdasarkan Permasalahan yang dipaparkan di atas, Menumbuhkan Semangat Pengusaha Muda Siswa SMA 6 Tangerang Selatan sebagai bentuk kepedulian dan pengabdian kepada masyarakat kepada Siswa SMA 6 Tangerang Selatan sangat tepat untuk dilaksanakan. Kebutuhan manusia dalam ilmu ekonomi bisa dikatakan tidak terbatas adanya. Semua keinginan ingin sekali terealisasi dengan mudah. Kondisi ini tentusaja tidak akan bisa terwujud tanpa adanya semangat pengusaha dari diri siswa. Alasannya, menumbuhkan semangat pengusaha muda ini sangat dibutuhkan sesuai dengan kebutuhan para siswa saat ini. Oleh sebab itulah pada PKM ini akan diberikan penyuluhan menumbuhkan semangat pengusaha muda siswa SMA 6 Tangerang Selatan.

$\begin{array}{ccc}\text { Manfaat } & \text { Pengabdian } & \text { Keapda } \\ \begin{array}{c}\text { Masyarakat } \\ \text { Kegiatan }\end{array} & \text { Pengabdian } & \text { Kepada }\end{array}$

Masyarakat dari tim dosen dan mahasiswa Universitas Pamulang hadir di SMA 6 Tangerang Selatan dalam bentuk pelatihan. Pelatihan ini akan melakukan pendekatan kekinian dengan metode diskusi berkelompok sehingga dapat lebih mudah dipahami oleh siswa SMA 6 Tangerang Selatan yang rata-rata adalah pemuda dan remaja siswa yang up to date dengan keadaan saat ini. Beberapa materi tentang kewirausahaan, khususnya untuk siswa yang mendapatkan uang dari pekerjaan sampingan bisa menjadi langkah awal yang tepat untuk dilaksanakan oleh remaja menuju kemandirian ataupun kebebasan finansial atau financial freedom. Hal ini tentu akan bisa didapatkan pada saat sang anak ataupun remaja telah lulus kuliah dan mendapat pekerjaan, atau justru sudah memiliki kehendak Semangat pengusaha muda sambilan (part time) saat masih sekolah pun kuliah.

Uang yang diterima sebagai upah Semangat pengusaha muda itu apabila dikelola dengan baik sangat memberi arti, dapat menjadi peranan penting dalam pembentukan jati diri anak guna mempersiapkannya di masa mendatang. 
Sangat diharapkan dari pelatihan ini para siswa di SMA 6 dapat Semangat pengusaha mudanya degan cara yang sederhana, dan dapat membentuk karakter hemat dan bijak dalam Semangat pengusaha muda.

\section{METODE}

Dalam kegiatan ini metode yang diterapkan diharapkan dapat memberikan kemudahan kepada para mahasiswa SMA 6 Tangerang Selatan. Metode yang digunakan adalah metode diskusi kelompok, sharing, tanyajawab, praktik yang di damping oleh pemateri. Pada metode penjelasan, setiap instruktur menyampaikan materi terkait dan membuat tampilan visual berupa slide power point yang ditampilkan ke layar dengan LCD proyektor.

Instruktur dalam menyampaikan penjelasan juga memasukkan unsur "sharing" atau berbagi pengalaman mengenai pengelolaan binis sederhana yang dilakukan oleh siswa dan materi yang telah dimiliki pemateri, dengan pertimbangan tersebut diharapkan dapat memberikan gambaran lebih jelas kepada peserta. Pada metode praktik, peserta berkelompok dan dengan pendampingan panitia mahasiswa bergantian menyusun perencanaan binis secara bergantian berkaitan dengan temannya. Peserta diajarkan bagaiman acara menyusun daftar kebutuhan dan mereka diperbolehkan memberikan penambahan daftar keinginan yang ingin mereka capai beserta strategi untuk mencapainya. Dengan demikian siswa tidak hanya sekedarterarah, dengan menggunakan pengelolaan binis sederhana yang jelas.

\section{HASIL DAN PEMBAHASAN}

Kegiatan Pengabdian Kepada Masyarakat ini berkaitan erat dengan menumbuhkan semangat pengusaha muda pada siswa. Pemahaman akan pentingnya melatih diri untuk berwirausaha haruslah disadari oleh usia remaja, dan sekolah menengah harus bisa membimbing setiap pelajar untuk dapat memahami bisnis dengan baik. Meskipun sebenarnya sekolah lebih utama, akan tetapi pemahaman tentang memulai bisnis perlu diberikan, untuk kemandirian individu. Fokus utama dalam aktivitas menumbuhkan semangat pengusaha muda ini memang harusnya disebar secara tersirat dalam mata pelajaran ekonomi dan akuntansi. Hal itu haruslah didasarkan pada intensitas perencanaan, kesiapan berpartisipasi dalam kehidupan sebagai pribadi yang independent, dan keterarahan individu-individu kepada tujuan. Didukung minat mereka untuk berbisnis yang sangat kuat. Masalah pengelolaan binis siswa di SMA dan SMK lebih mengacu pada hal-hal berikut:

Perilaku yang konsumtif sering tak disadari. Alhasil, banyak orang yang begitu konsumtif sehingga perlahan binisnya menjadi bermasalah. Uang yang diterima mungkin tinggi namun tidak ada yang bisa ditabung di akhir bulan. Bila Siswa pernah terpikir kenapa belum ada dana yang ditabung padahal Siswa sudah memiliki uang saku yang melebihi jumlah pengeluaran yang seharusnya, mungkin perilaku konsumtif Siswa yang menjadi penyebabnya. Remaja yang konsumtif biasanya membeli barang yang sebenarnya tidak terlalu ia butuhkan, membelanjakan uang untuk keperluankeperluan yang tidak penting, gaya hidup yang terlalu hura-hura, dan sebagainya. Untuk itui dibuatlah solusi, tahan selera Siswa. Siswa harus mementingkan kebutuhan; mana yang harus dipenuhi dan mana yang sebenarnya kurang penting, dalam artian, terpenuhi atau tidaknya hal tersebut tidak akan mempengaruhi Siswa.

Bila Siswa sudah memiliki suatu barang, usahakan agar tidak membeli barang dengan fungsi yang sama namun harganya lebih mahal. Buat apa punya dua barang dengan fungsi yang sama? Meski mungkin, yang lebih mahal tentu lebih bagus dan lengkap fungsinya. Siswa juga harus tahu tujuan Siswa dalam mengalokasikan dana. Bila Siswa tidak bijak dalam menetapkan tujuan pembelanjaan, Siswa hanya akan membelanjakan uang Siswa untuk berbagai keperluan yang sebenarnya tidak perlu.

Tak bisa dipungkiri, anak muda memang senang menghabiskan waktu untuk berkumpul/nongkrong, menikmati sesuatu yang sedang tren, berusaha untuk terus sejalan dengan perkembangan terkini dalam berbagai bidang, dan sebagainya. Apalagi bagi siswa yang belum memiliki tanggungan atau masih lajang. Karena belum memiliki tanggungan, ia merasa belum bertanggung jawab untuk Semangat pengusaha mudanya 
karena pendapatannya hanya untuknya. Jadi, anggapan bahwa penghasilannya hanya untuknya seakan melekat dalam dirinya.

Oleh karena itu, siswa kerap menghabiskan uang untuk memanjakan dirinya tanpa disadari. Perlahan binisnya pun menjadi tak terkontrol. Setiap bulan uang habis tanpa sisa untuk ditabung, menunggu bulan depan untuk gajian kembali. Bila pun ada sejumlah dana yang tersisa, Siswa umumnya menggunakan uang tersebut untuk bersenang-senang, bukan menabung atau berinvestasi.

Solusi sepenuhnya ada di dalam diri Siswa. Harus mencoba untuk menemukan pola yang tepat ketika membelanjakan uang. Bila Siswa merasa bahwa selama ini sudah terlalu banyak menghamburkan uang untuk bersenang-senang, mungkin Siswa benar. Meskipun sekarang ini Siswa belum memiliki tanggungan, siswa harus mencoba untuk berhemat, mengatur pengeluaran dengan membandingkan mana yang prioritas dan mana yang tidak begitu mendesak.

Dana darurat tidak hanya permasalahan yang harus dipersiapkan oleh orang akan sangat bermanfaat bila nantinya ada saja ke dewasa. Siswapun memerlukan ini untuk membayar perluan mendadak yang harus dipenuhi sementara uang Siswa tidak cukup untuk menutupinya. Siswa mungkin belum terpikir untuk mempersiapkan dana darurat, atau bila pun sudah terpikir, uang Siswa sudah habis lebih dulu sebelum benarbenar memulai untuk menyiapkan dana darurat.

Solusinya dari sekarang Siswa harus bisa menyisihkan sejumlah uang yang kemudian dialokasikan khusus untuk dana darurat. Misalnya, dalam sebulan, cobalah sisihkan uang saku Siswa per bulan, misalnya 20\% dari gaji Siswa, khusus untuk dana darurat. Nantinya, jangan pernah sentuh uang tersebut selain dari keperluan mendesak.

Menabung juga menjadi salah satu cara mengelola dan membentuk tujuan binis yang baik. Katakanlah Siswa berencana menikah di usia 28 tahun. Bila Siswa sudah merencanakan hal tersebut maka Siswa juga harus mempersiapkan binis untuk biaya pernikahan. Kecuali bila ada donatur yang membiayai atau pernikahan Siswa disponsori. Bila tidak ada, maka mulailah menabung. Paksa diri Siswa untuk memulai, dan biasakan agar tetap konsisten seturut waktu.

Jangan sampai hanya di bulan pertama saja Siswa semangat menabung, namun di bulan berikutnya Siswa sudah berhenti. Konsisten dalam menabung sangat diperlukan, baik dalam hal frekuensi waktu maupun jumlah dana yang bisa ditabung. Bila perlu, tambah jumlah dana yang bisa Siswa tabung setiap bulannya. Paksa diri Siswa untuk bisa menyisihkan uang setiap bulannya untuk ditabung. Seberapa pun itu, asal konsisten, perlahan akan membentuk tabungan Siswa sehingga bisa diSiswalkan di kemudian hari.

Salah satu masalah binis yang sering dihadapi Siswa adalah kurangnya kesadaran bahwa seturut waktu uang yang ia miliki akan berkurang nilainya terutama ketika inflasi terjadi. Setiap Siswa kerap mengabaikan fakta bahwa pendapatan hari esok bisa saja lebih rendah ketimbang hari ini. Maka dari itu demi mempersiapkan diri dari kemungkinan-kemungkinan yang menyesakkan ke depannya, jangan biarkan uang yang Siswa miliki saat ini diam tak menghasilkan. Siswa bisa mencari sumber penghasilan baru seperti berbisnis atau memulai pekerjaan sampingan. Siswa bahkan bisa berinvestasi terutama karena beragam instrumen investasi.

\section{PENUTUP}

Mencurahkan permasalahn binis yang ternyata tidaklah sederhana yang seperti perkiraan sebelumnya. Seluruh perserta diajak mengutarakan permasalahan untuk kemudian dipecahkan bersama-sama. Kebanyakan siswa yang menjadi peserta masih belum memiliki dasar yang kuat dalam pengelolaan binis, sehingga gaya hidup mereka cenderung boros, impulsif dan menjadi siswa yang sangat konsumtif.

Pengelolaan binis sederhana mendapatkan hasil yang sangat baik. Siswa lebih peka terhadap diri dan ke mulai dapat mengambil sikap untuk menentukan apasaja yang harus diraih dan ditempuh untuk mewujudkan rencana binisnya tersebut, meski belum terkondidikan dengan baik, mereka mampu memberikan pemaparan akan perncanaan binisnya di masa yang akan datang. Kegiatan ini juga menjadi inspirasi 
bagi siswa yang belum memulai kegiatan usaha, namun sudah memiliki semangat usaha dalam dirinya.

\section{DAFTAR PUSTAKA}

Achmad, Nur. 2015. Kewirausahaan: Suatu Alternatif Lain Menuju Kesuksesan. Surakarta: BPK FEB UMS.

Achmad, Nur dan Saputro, Edy Purwo. 2015. Isu Riset Kewirausahaan. Jakarta: Direktorat Penelitian Pengabdian Masyarakat Dirjen Dikti.

Achmad, Nur., Saputro, Edy Purwo dan Handayani, Sih. 2016. Kewirausahaan di Era Digital. Jakarta: Direktorat Penelitian Pengabdian Masyarakat Dirjen Dikti.

Akbar, I. R., Prasetiyani, D., \& Nariah, N. (2020). Pengaruh Motivasi Terhadap Kinerja Karyawan Pada Pt. Unggul Abadi Di Jakarta. Jurnal Ekonomi Efektif, 3(1)

Akintoye, A. S dan MacLeod, M. J. 1996.Risk Analysis and Management in Contruction. International Journal of Project Management. Vol. 15, No. 1, pp. 31-38.

Barsah, A., Sudarso, A. P., \& Sunarsi, D. (2020). Analisis Pengaruh Pengajaran dan Sertifikasi Guru terhadap Kompetensi Guru pada Sekolah Menengah Kejuruan Di Wilayah Parung Panjang Kabupaten Bogor. Journal of Education, Humaniora and Social Sciences (JEHSS), 3(2), 650-657.

Dewi, R. V. K., Sunarsi, D., \& Akbar, I. R. (2020). Dampak Penggunaan Teknologi Informasi dan Komunikasi Terhadap Minat Belajar Siswa di SMK Ganesa Satria Depok. Jurnal Ilmiah Wahana Pendidikan, 6(4), 1001-1007.

Drucker. Peter. F. 1993. Inovasi Dan Kewiraswastaan. Jakarta:

Erlangga. Effendy, Mochtar. 2010. Kewirausahaan (Entrepreneurship) Tuntunan Untuk Praktisi. Yayasan Penerbit Al-Mukhtar: Palembang.

Gunartin, G., Mulyanto, E., \& Sunarsi, D. (2020). The Role Analysis of Waste
Bank in Improving the Community's Creative Economy (Study at Ketumbar Pamulang Waste Bank). Budapest International Research and Critics Institute (BIRCI-Journal): Humanities and Social Sciences, 3(4), 3262-3269.

Handoko T. Hani. 2003. ManajemenEdisi 2. Yogyakarta: BPFE-Yogyakarta

Hermawati, R., Sugiyarti, L., Handayani, R., Sunarsi, D., Alfiah, S., \& Maddinsyah, A. (2020). The Effect of Trilogy Leadership Style and Organization Culture on School Performance: Evidence form Indonesian Senior High School. PalArch's Journal of Archaeology of Egypt/Egyptology, 17(6), 8512-8537.

Muhamad Apep Mustofa, Azhar Affandi. (2020). Pengaruh Ekuitas Merek terhadap Keputusan Pembelian Mobil Jaguar dan Land Rover pada PT. Wahana Auto Mandiri di Jakarta. Jurnal Tadbir Peradaban. Volume 1 Issue 1 Pages 48-53

Noviyanti, I., Hayati, F. A., Nufus, K., Maduningtias, L., Rostikawati, D., Sunarsi, D., \& Effendy, A. A. (2020). Did Virtual Transformational Leadership Style Influence Schools Performance? Answer form Indonesian Senior High Schools. PalArch's Journal of Archaeology of Egypt/Egyptology, 17(6), 8438-8461.

Nurjaya, N., Affandi, A., Erlangga, H., Sunarsi, D., \& Jasmani, J. (2021). The Effect of Product Promotion and Innovation Activities on Marketing Performance in Middle Small Micro Enterprises in Cianjur. Budapest International Research and Critics Institute (BIRCIJournal): Humanities and Social Sciences, 4(1), 528-540.

Paeno, P., Kasmad, K., Sunarsi, D., Maddinsyah, A., \& Supiyan, D. (2020). Pemanfaatan Sampah Plastik Untuk Kerajinan Rumah Tangga Taman Belajar Kreatif Mekar Sari. Baktimas: Jurnal Pengabdian pada Masyarakat, 2(1),57-61. 